\title{
The Impact of Teaching through Twitter on Students' Vocabulary Learning: A Case Study of Qassim University
}

\author{
Huda Sulieman Alqunayeer ${ }^{1, *}$ \\ ${ }^{1}$ Qassim University, Al-Qassim, Kingdom of Saudi Arabia \\ *Correspondence: Qassim University, Al-Qassim, Kingdom of Saudi Arabia. Tel: 966-504-889-474. E-mail: \\ sadia.zamir@hotmail.com
}

Received: February 19, 2016

Accepted: March 7, 2016 Online Published: June 24, 2016

doi:10.5430/wjel.v6n2p35

URL: http://dx.doi.org/10.5430/wjel.v6n2p35

\begin{abstract}
The purpose of this study is to investigate the effect of using Twitter on first level bachelors students' achievement in English vocabulary. The first goal of the present study was to determine the effectiveness of using Twitter to improve the learners' L2 vocabulary. To achieve this goal, third-year students of English as a target language were tested on their vocabulary knowledge after treatment. The second goal of this study was to find out if there any significant differences between the effect of traditional teaching methods and using Twitter in teaching vocabulary. To achieve this goal, the participants in both groups were tested, and their scores were then compared. The sample in the study consisted of 160 during the second semester of 2015/1436. Over eight weeks, the experimental groups were taught by using the social network Twitter, while the control groups followed the traditional way of teaching vocabulary, i.e. explaining the words in simple English, giving hints or gestures, and using pictures or flashcards. The findings show that there is an increase in students' vocabulary achievement in both groups, but the experimental group seems to perform better than the control group. The researcher concludes with recommendations for further studies on the effectiveness of using Twitter to improve student achievement in other English skills areas.
\end{abstract}

Keywords: social network; Twitter; English vocabulary; teaching methods; experimental research

\section{Introduction}

The Kingdom of Saudi Arabia is improving day-by-day in the field of education, but the level of achievement in learning English as a foreign language is far below than that of the other subjects. According to Alshumimeri (2003), teachers have pointed out that students leave one stage of education for another one without the ability to speak or make a short conversation. Students consider English as a language to pass during examinations, so they do not give any emphasis to acquiring proficiency in English. English has a strong presence in the Saudi educational system. It is the main foreign language taught in Saudi Arabian public schools from grade four at primary schools and from kindergarten at private schools. Fareh (2010) pointed out that the challenges of EFL programs in the Arab world are such things as inadequate teaching methodology, lack of motivation, and teacher-centered activities, etc. Alderman (1999) has reported that motivation "leads to possibilities for fostering the development of students' potential". Therefore, if teachers find out how to motivate students and what methods are effective in teaching them, then students will be more proficient in learning English.

The teaching of English as a foreign language has been enormously changed in the last few decades. Currently, the methodologies of English language teaching focus on giving learners opportunities to communicate (Ellis, 2008). However, most students are afraid to speak out loud and communicate in front of the classroom. Therefore, teachers should enable students to enjoy their English language learning and to be motivated to learn English. If not, low levels of proficiency will continue to be a problem. "If you always do what you have always done, you will always get what you have always got. If you do not like what you got, then change it" (Henry Ford).

Female in Saudi Arabia rarely use English because they have few chances to meet strangers or travel to a place where the speakers are native English speakers. However, mobile devices and applications (apps) are changing the way people learn English. Our world today is obsessed with mobile phone apps and technology. These apps-such as WhatsApp, Twitter, Facebook, and Instagram — are widely used by people of different ages, especially teenagers, 
in Saudi Arabia. All of these apps have English names, and all of the terminology used in them is also in English such as like, share, favorite, retweet, group, follow, etc.

By using social networking, more possibilities to increase the exposure to and retention of vocabulary are provided. Using apps enhances learning opportunities through the availability of more space to document information by using images, links to clips, and written debate. In such a setting, students can feel free to ask about things that are unclear, discuss topics with each other, and think about and have time to arrange their answers. Therefore, social networking sites give students the chance to build their English vocabulary, which means that they will later use English as part of their communication with non-Arabic speakers.

Therefore, there is a need to see the impact of common social networking sites (e.g.twitter) on the vocabulary learning of English language learners. When we talk about English language teaching, we see that all language skills hold prime importance. Vocabulary of a language provides the learner a store house of information to enrich his communication. As, Harmer (1993) states, "If language structures make up the skeleton of language, then it is vocabulary that provides the vital organs and the flesh".

\subsection{Statement of the Problem}

Teaching English vocabulary is an important subject discussed and explained in detail by linguists and methodologists. Teachers are faced with the challenge of how to teach vocabulary and to find the best strategies to teach it. This study depends upon the rationale that learners who have lists of vocabulary can participate effectively in communication.

\subsection{Research Questions}

The study attempts to answer the following questions:

1- Is there any significant difference between the effect of traditional teaching methods and using Twitter in teaching vocabulary?

2- Does using Twitter in teaching vocabulary have a positive effect on students' vocabulary achievement?

\subsection{Significance of Research}

Due to the importance of vocabulary in mastering any language and also as a key factor in communicating in general, teachers still have not yet found better techniques to teach it. There are various strategies to teach vocabulary and numerous studies in this area that address the same issue in one way or another, but this study attempts to add a new strategy in teaching. This study tries to use Twitter, in particular, in the process of teaching vocabulary. Many studies discuss different strategies in teaching vocabulary and other skills in the English language such as using pictures, novels, stories, flashcards, and games. Nonetheless, teachers realize that they are teaching a new generation that is connected online with each other by using social networks. Therefore, the main question teachers should ask themselves is do traditional strategies still work these days?

\section{Literature Review}

Twitter is a social networking site. What can be called "micro-blogging users" can "tweet" anytime, using smart phones or laptops, within the limited number of 140 characters. Also, users can add any links they desire to blogs, YouTube, and images. This limitation in the length of tweets is advantageous because it is easier to read the heart of the matter without spending time on useless details.

There have been many articles and studies published in the last 10 years about social networking sites and their relation to improving education. Hoffman (2009) investigates a number of examples of social networking tools for educators and then explores in greater depth the use of a particular one, Ning, in a distance learning course. Students who participated in this study ranged in age from 20-50 and attended the University of Hawaii. The results show a positive effect on the course by providing a formal structure for required discussions, helping students as they work on collaborative projects, and personalizing student interactions through the sharing of informal comments and messages.

Bake-Plock (2009) shared on his blog his own positive experience in using Twitter in the classroom: "I see Twitter as an excellent resource for assessing several skills that are fundamental to learning and living such as: the ability to make mistakes and immediately get positive critical feedback" (post on May 14, 2009). This article contains a list of the best practices that can be used for Twitter to enhance the classroom. This list includes such items as building the students' vocabulary through open-ended questions and discussion and strengthening their grammar by providing 
them with immediate corrections. Twitter can also developing the student skill in searching, doing collaborative work, and collecting sources on topics.

Also, Ferriter et. al (2011) supports this idea and suggests that Twitter helped to provide him with a sense of the strengths and weakness of the individual students, which is what he called "differentiation as a learner." Furthermore he found Twitter to be a great resource in exchanging ideas with other teachers, offering suggestions, asking questions, and celebrating successes.

Ally (2010) confirmed the effectiveness of social media like Twitter in improving students' attention, engagement, and participation. Also, it is useful in allowing students to discuss lessons with the teacher and ask questions at any time and in any place away from the limited time of the classroom period.

In the study of the effect of Twitter on college students' engagement and grades done by Junco, Heibergert, and Lokent (2011), 125 students were selected to determine if using Twitter can affect students' engagement and grades. The study showed an increase in acquiring the material and an improvement in student grades as well as the communication between students and teachers outside the classroom.

In another study by Welch \& Bonnan-White (2012), using Twitter inside the classroom helped to increase students' engagement. By adopting a quasi-experimental approach, the result was that tweeting about an opinion or an answer to a multiple choice question inside the classroom was enjoyable and an engagement strategy in teaching.

Another study about using Twitter outside the classroom was conducted by Nora Al-Otabi (2013). Her study aimed to investigate the effectiveness of Twitter on academic achievement and the development of cooperative learning skills among students in a computer curriculum. The study followed a quasi-experimental design and had a positive result in favor of the experimental group.

Furthermore, Chuah and Ch'ng (2013) support this idea and suggest that using Twitter to learn vocabulary helps increase the proficiency of students. They also investigated how Twitter allows incidental learning of vocabulary among low proficiency students. The findings revealed minimal improvement in the students' vocabulary obtained through instructor tweets.

The review of the related literature has revealed that some researchers, such as Bake-Plock (2009), Ferriter (2010), and Chuah and Ch'ng (2013), believe that Twitter helps students gain new vocabulary intentionally and incidentally, enhancing student grades and engagement and developing student skills. The present study aims to use Twitter for educational purposes, which will provide Saudi Arabian female students an opportunity to improve their English language skills by using Twitter. Next to the problem of the rarity of the use of English outside the classroom, there is a problem that females, in particular, have much less opportunity to use the language and to deal with any native speakers than males. Therefore, females in Saudi Arabia need an opportunity to gain new English words or at least have a chance to use their vocabularies they have learned inside the classroom. Hence, using Twitter in teaching or following English teacher accounts on Twitter will enable them to learn English more effectively.

\section{Methodology}

Quantitative research was adopted in order to arrive at answers to the research questions. A questionnaire was given to200 students, and the total of 160 questionnaires were received. The purpose of this questionnaire was to control the external variables. The study follows an experimental approach in which one independent variable is investigated to check out if it has an impact on the dependent variable. The independent variable in the present study is Twitter as a strategy in teaching, and the dependent variable is students' vocabulary scores. The study had 160 participants who were divided into two groups (80 students as the control group and 80 students as the experimental group) based on their answers to the questionnaire. The experimental groups were taught by using the social networking site Twitter, while the control groups were taught using the traditional ways of teaching vocabulary-i.e., translating new words into the mother tongue, giving hints or gestures, and using pictures or flashcards - as they emerged in reading or listening to text. 
Table 1. Design of the Study

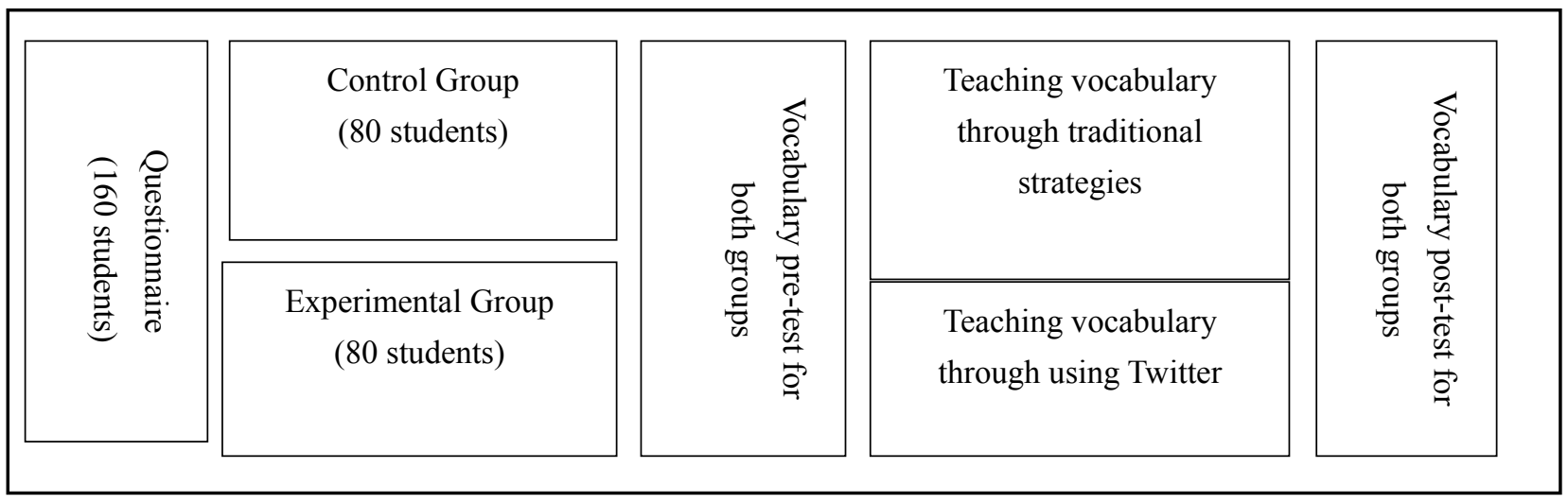

\section{Analysis}

The researcher used different statistical forms using a statistical program (SPSS) to analyze the collected data results. A t-test for the samples was used to analyze the difference between the means of scores in the study subjects in the pre- and post-tests. Scores of the study samples on the pre- and the post-tests were compared. Tables were also used to clarify and present these data with analysis and interpretation. Results of comparisons revealed an outstanding improvement in the subjects' vocabulary knowledge.

\subsection{The Equivalence between the Experimental and Control Groups}

The achievement test was used as a pre-test in order to determine the homogeneity of the groups before applying the study. A t-test for independent groups was used to compare the mean scores of the two groups as shown in Table 2.

Table 2. The Equivalence of the Two Groups

\begin{tabular}{lcccccccc}
\hline Group & N & $\begin{array}{c}\text { Mean } \\
(\mathbf{M})\end{array}$ & $\begin{array}{c}\text { Std } \\
\text { Deviation }\end{array}$ & F & Sig & t & df & $\begin{array}{c}\text { Sig } \\
\text { 2.Tailed }\end{array}$ \\
\hline $\begin{array}{l}\text { Experimental } \\
\text { Control }\end{array}$ & 80 & 22.57 & 4.09 & 5.741 & 0.018 & 0.068 & 158 & 0.946 \\
\hline
\end{tabular}

The above table shows that there was a significant difference of 0.05 between the mean scores of experimental and control groups. The result of the t-test was $(\mathrm{t}(158)=0.068, \mathrm{p}=1.96) ; \mathrm{f}(79,79)=5.741, \mathrm{p}=1.53)$. The mean scores of the pre-tests of both groups were very close to each other (Group $\mathrm{A}=22.57$, Group $\mathrm{B}=22.52$ ). It is assumed, therefore, that both groups had similar knowledge about the target words before they were exposed to the treatment. This indicated the homogeneity of the study's groups.

\subsection{Testing the First Hypothesis}

The first hypothesis stated: "There is no statistically significant difference $(\alpha \leq 0.05)$ between the mean scores of the experimental group and the control group on the post-test in favor of the experimental group."

To test this hypothesis, the researcher used a t-test for the independent groups to measure the differences between the mean scores of experimental and control groups on the achievement test. The results are presented in Table 3.

Table 3. T-test that Shows the Differences between Mean Scores of the Experimental and Control Groups in the Post-Test

\begin{tabular}{lccccccccc}
\hline Strategy & N & $\begin{array}{c}\text { Mean } \\
(\mathbf{M})\end{array}$ & $\begin{array}{c}\text { Std } \\
\text { Deviation }\end{array}$ & F & Sig & T & df & $\begin{array}{c}\text { Sig } \\
\text { 2.Tailed }\end{array}$ & $\begin{array}{c}\text { Effect } \\
\text { Size }\end{array}$ \\
\hline Using Twitter & 80 & 27.37 & 4.49 & .08 & 0.77 & 3.3 & 158 & 0.001 & 0.06 \\
Traditional method & 80 & 24.98 & 4.61 & & & & & &
\end{tabular}


Table 3 indicates that there was a significant difference $(\mathrm{t}(158)=3.3, \mathrm{p}=1.96)$ between the mean scores of the experimental group $(\mathrm{M}=27.37, \mathrm{SD}=4.49)$ and the control group $(\mathrm{M}=24.98, \mathrm{SD}=4.61)$ on the post-test in favor of the experimental group.

Hence, the researcher rejected the null hypothesis and accepted the alternative hypothesis: "There are statistically significant differences $(\alpha \leq 0.05)$ between the mean scores of the experimental group and the control group on the post-test in favor of the experimental group."

To show the extent of the Twitter effect on the experimental group's achievement in vocabulary, the study applied the "effect size" technique.

\subsection{The Effect Size}

To calculate the effect size, the researcher used Eta square " $\eta^{2}$ " by using the following equation (Affan, 2000):

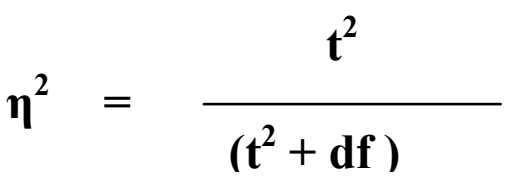

$$
\mathrm{df}=\mathrm{n}_{1}+\mathrm{n}_{2}-2
$$

Table 4. The Criteria of the Effect Size

\begin{tabular}{cccc}
\hline Scale & \multicolumn{3}{c}{ The significance of effect size } \\
\hline $\boldsymbol{\eta}^{2}$ & Small & Medium & Large \\
& 0.01 & 0.06 & 0.14 \\
\hline
\end{tabular}

Table 5. The Effect Size of Using Twitter on the Experimental and the Control Groups' Achievement on the Post-Test

\begin{tabular}{llllll}
\hline Test & Df & T & $\boldsymbol{\eta}^{2}$ & D & Effect size \\
\hline Post-test & 158 & 3.3 & 0.06 & 0.001 & Medium \\
\hline
\end{tabular}

Table 5 shows that the effect size of using the Twitter strategy on developing achievement is medium $\left(\eta^{2}=0.06\right)$. This means that $6 \%$ of the variance in the scores of the experimental group is due to using Twitter.

\subsection{Testing the Second Hypothesis}

The second hypothesis stated: "There are no statistically significant differences $(\alpha \leq 0.05)$ on the achievement test in favor of the group using Twitter in teaching vocabulary."

To test this hypothesis, the researcher used a t-test for the independent groups to measure the differences between the mean scores of experimental and control groups on the achievement test. The results are presented in Table 6 .

Table 6. T-Test of the Differences between Using Twitter and Traditional Methods

\begin{tabular}{cccccccccc}
\hline $\begin{array}{l}\text { Experimental } \\
\text { Group }\end{array}$ & $\mathrm{N}$ & $\begin{array}{c}\text { Mean } \\
(\mathrm{M})\end{array}$ & $\begin{array}{c}\text { Std } \\
\text { Deviation }\end{array}$ & F & Sig & T & Df & $\begin{array}{c}\text { Sig } \\
\text { 2. Tailed }\end{array}$ & $\begin{array}{c}\text { Effect } \\
\text { Size }\end{array}$ \\
\hline Pre-test & 80 & 22.57 & 4.09 & 1.59 & 0.20 & 7.05 & 158 & 0.000 & 0.23 \\
Post-test & 80 & 27.37 & 4.49 & 1.59 & \\
\hline
\end{tabular}

Table 6 indicates that there was a significant difference $(\mathrm{t}(158)=7.05)$ between the mean scores of the students who were taught by Twitter $(\mathrm{M}=22.57, \mathrm{SD}=4.09)$ and the students who were taught by traditional methods $(\mathrm{M}=27.37$, $\mathrm{SD}=4.49$ ) on the achievement test in favor of those using Twitter.

Table 7. The Effect Size of Using Twitter on the Pre- and the Post-Test of the Experimental Group

\begin{tabular}{llllll}
\hline Test & Df & T & $\boldsymbol{\eta}^{2}$ & D & Effect size \\
\hline Pre-post & 158 & 7.05 & 0.23 & 0.00 & Large \\
\hline
\end{tabular}


Table 7 shows that the effect size of using the strategy on developing achievement is large $\left(\eta^{2}=0.23\right)$. This means that $23 \%$ of the variance in the scores of the experimental group was due to using Twitter to teach vocabulary.

Hence, the researcher rejected the null hypothesis and accepted the alternative hypothesis: "There are statistically significant differences $(\alpha \leq 0.05)$ on the achievement test in favor of the group using Twitter in teaching vocabulary."

\section{Discussion}

The results of the study indicated that students' vocabulary achievement, in two groups who were taught by using Twitter or traditional strategies, was enhanced, but the experimental group seems to be better off than the control group. That is, the experimental group students had significantly better vocabulary score gains as compared to the control group students at the end of the study. Both groups followed the same course book, Say It in English, which provided the students with a number of the new vocabulary words. The difference lies in the strategy that the researcher used with the groups to teach vocabulary. The experimental group was taught vocabulary through using Twitter as a new strategy, while the control group was taught by using traditional strategies.

The experimental group students in the present study were interested during the teaching of vocabulary by the suggested strategy. Students who participated in this study found this strategy more effective than the traditional ones due to the ability to receive help and feedback from the teacher immediately. Also, using SNSs reduces the gap between the students and the teacher. This is the opposite of the results of a survey conducted by Nemetz, Aliken, Cooney, and Pascal (2010) that found out that students did not adapt themselves to communicating freely with their teacher.

In addition, the researcher found that the other positive effect of using Twitter in teaching vocabulary to the pupils is that Twitter gave the pupils an opportunity to improve other skills, besides just knowledge, such as reading, writing, and searching. All of these skills were observed by the researcher on the achievement test, and students acquired them unintentionally by reading tweets written by the researcher, searching for answers independently, and then writing the answer as a tweet. On the other hand, pupils were totally dependent on the teacher for input resource and therefore no place for self-development.

Another observation is the willingness of the pupils who used Twitter to make mistakes without being afraid, which was useful especially for shy students who are afraid of being laughed at by their friends. Also, learners have a chance to think without stress before writing their answers, which is one of the essential factors for learning. Furthermore, this study shows a positive effect on students' grades and engagement, which is clear from the increasing scores of their assessments. Thus, the students' freedom to answer after thinking without fear and stress and having a chance to search for the answer from several sources mainly helped in increasing grades and educational achievement.

These results are in accordance with the results of most of the studies mentioned before. The results of the present study concluded that using Twitter as a strategy to teach vocabulary helps to increase the achievement of students as well as improves their writing and researching skills. So, the technological strategies and using SNSs in teaching had positive effects on student achievement, as shown in Table (6).

However, what about the traditional strategies - do they still have the same positive effect on students' vocabulary achievement as proved in previous studies? The present study shows that both methods enhanced the vocabulary skills of the learners from the pre-test to the post-test. The mean score of the pre-test of the control group is 22.52 and the mean score of the post-test is 24.98 , which means traditional strategies still have positive effects on student achievement. Nonetheless, the results of the experimental group show that the mean score of the pre-test of the control group is 22.57 and the mean score of the post-test is 27.37 , which seems to be better than the control group. On top of that, results show that the experimental group improved more than the controlled group, as shown in Figure 1.

\section{Summary of Findings}

The following findings were observed:

1- There were statistically significant differences in the total average score in vocabulary achievement between the pupils who learned though using Twitter (experimental group) and those who learned through the traditional strategy (control group) in favor of the experimental group with a large effect size. 
2- There were statistically significant differences in the average score on the pre- and post-test of the experimental group in favor of the post-test.

3- There were statistically significant differences in the average score on the pre- and post-test of the control group in favor of the post-test.

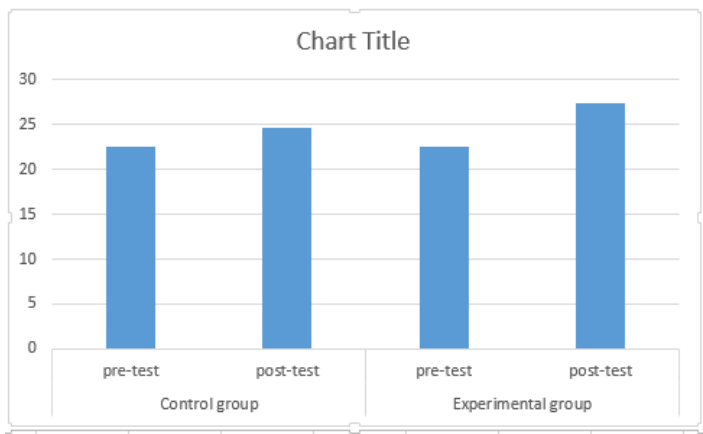

Figure 1. The Difference between the Improvements between the Two Groups

\section{Conclusion \& Recommendations}

This study aims at investigating the effectiveness of using social networking (Twitter) in developing the English vocabulary skills of graduate level students. The study follows the experimental approach in which one independent variable (Twitter as a strategy in teaching) is investigated to check out if it has an impact on the dependent variable (students' vocabulary scores). The study had 160 participants who were divided into two groups (80 students as a control group and 80 students as an experimental group) based on their answers to a questionnaire. Over eight weeks, the experimental groups were taught by using the social network Twitter, while the control groups followed the traditional ways of teaching vocabulary, i.e., translating new words into the mother tongue, giving hints or gestures, and using pictures or flashcards.

The first goal of the present study was to determine the effectiveness of using Twitter to improve the learners' L2 vocabulary. To achieve this goal, third level students of English as a target language were tested on their vocabulary knowledge after treatment. The second goal of this study was to find out if there are any significant differences between the effects of traditional teaching methods and using Twitter in teaching vocabulary. To achieve this goal, the participants in both groups were tested and then their scores were compared.

The first research question addressed was: Is there a significant difference between the effect of traditional teaching methods and using Twitter in teaching vocabulary? The findings show that there is an increase in students' vocabulary achievement in both groups, but the experimental group seems to be better off than the control group. There is a statistically significant difference between the means of scores obtained by subjects of the control $(\mathrm{M}=24.98)$ and experimental $(\mathrm{M}=27.37)$ groups on the vocabulary post-test. Thus, the first hypothesis, "There are statistically significant differences $(\alpha \leq 0.05)$ between the mean scores of the experimental group and the control group on the post-test in favor of the experimental group," is affirmed.

The second research question addressed if using Twitter in teaching vocabulary had a positive effect on students' vocabulary achievement. The findings show that there is an increase in students' vocabulary achievement in the experimental group. There is a statistically significant difference between the means of the scores obtained by subjects on the pre-test $(M=22.57)$ and the post-test $(M=27.37)$ of vocabulary. Thus, the second hypothesis, "There are statistically significant differences $(\alpha \leq 0.05)$ on the achievement test in favor of using Twitter in teaching vocabulary," is affirmed.

\subsection{Conclusion}

Social networking sites (Twitter) are a modern strategy that is worth using in teaching vocabulary in English as a foreign language classes at undergraduate level. Although this study focused on the development of vocabulary achievement, it becomes evident that the writing of tweets and choosing suitable images for the words allowed students to extend their writing, reading, and researching skills. The techniques of writing and reading help students to increase memory retention of the words and to reduce spelling mistakes. The present study suggests that Twitter be used not only for fun and communication but, more significantly, for useful practice in language lessons, thus 
leading toward the goal of improving learners' knowledge. These advantages of using Twitter may work in learning vocabulary or other skills and are an effective and interesting method that can be applied in any classroom. Although some students like to learn independently and despite the positive effects of using Twitter, many students still prefer actual classroom discussions instead of those in Twitter.

\subsection{Recommendations}

Based on the findings of this study, the following can be recommended;

1. Teachers should encourage the use of social networking sites in teaching and learning.

2. Teachers should change the methods and strategies of teaching from traditional ones to communicative strategies that are based on the students' real involvement in the teaching-learning process.

3. Teachers should change their role from instructors who dominate the class into educators whose role is to guide and help students to communicate and acquire the language.

4. Teachers should teach English by using interesting strategies instead of focusing on only traditional ones.

5. Students should use technology and social networking sites in learning English and other skills.

\subsection{Suggestions for Further Research}

In order to extend the findings of this study, the researcher recommends the following:

1. Replication of this study in different settings such as secondary schools or other educational institutions.

2. A further study is needed to replicate the study with different learners of different age groups.

3. The same experiment with male students within the same age range would be necessary to confirm the findings of this study.

4. Experimental studies regarding this research topic could also be done to see how the effective influences of using Twitter help in improving students' writing skills.

5. Further research is needed to investigate the effect of using Twitter on developing reading skills.

6. Since integrating social networking sites is a new trend in Saudi Arabia, researchers need to investigate the aptitude of Saudi students in using and integrating such technology.

\section{References}

Affann, A. (2000). The Effect Size in Educational Researches. Palestinian educational studies magazine, 3(6).

Alderman, M. K. (1999). Motivation for achievement: Possibilities for teaching and learning. Mahwah, NJ: Lawrence Erlbaum.

Ally, Mustafa. (2012). Student Attention, Engagement and Participation in a Twitter-friendly Classroom, in ACIS 2012: Location: Proceedings of the 23rd Australasian Conference on Information Systems, ACIS, pp. 1-9.

Al-Shumaimeri, Y.A.N. (2003). A study of classroom exposure to oral pedagogic tasks in relation to the motivation and performance of Saudi secondary learners of English in a context of potential curriculum reform. Unpublidhed Ph,D. Thesis, University of Leeds, Leeds.

Blake-Plock, Shelly. (2009). Best Practices in a Twitter-Enhanced High School Classroom. Teach Paperless, Seeking Social Solutions to the Mysteries of $21^{\text {st }}$ Century Teaching and Learning. Posted on May 14, 2009. Retrieved 15, August 2015 from http://teachpaperless.blogspot.com/2009/05/best-practices-in-twitter-enhanced-high.html

Bridgt, K., Welch \& Bonnan-White, J. (2012).Twittering to increase student engagement in the university classroom. Knowledge Management \& E-Learning: An International Journal, 4(3), 325-345.

Chuah, Kee- Man, Ch'ng, Looi-Chin. (2013). Tweeting the Words Away: Rethinking the Use of Twitter in Vocabulary Learning. MELTA International Conference 2013.

Ellis, R. (2008). The study of second language acquisition. Oxford: Oxford University Press.

Fareh, Shehdeh. (2010). Challenges of teaching English in the Arab World: Why can't EFL Programs deliver as expected?. Procedia Social and Behavioral Sciences, 2(2010), 3600-3604. http://dx.doi.org/10.1016/j.sbspro.2010.03.559 
Ferriter, William M., Ramsden, Jason T., \& Sheninger, Eric. C. (2011). Communicating and Connecting with Social Media (Essentials for Principals). Solution Tree Press. USA.

Junco, R., Heiberger, G., \& Loken, E. (2011). The effect of Twitter on college student engagement and grades. Journal of Computer Assisted Learning, 27(2), 119-132. http://dx.doi.org/10.1111/j.1365-2729.2010.00387.x

Harmer, J. (1993). The practice of English Language Teaching. New York: Longman.

Hoffman, E. (2009). Evaluating Social Networking Tools for Distance Learning. In Proceedings of TCC - Teaching Colleges and Community Worldwide Online Conference, pp. 92-100

Nemetz, R., Aiken, K., D., Cooney, V., \& Pascal, V. (2010). Should Faculty Use Social Networks to Engage with Students? Retrieved May, 6, 2013 from http://www.mmaglobal.org/JAME-Archive/JAME_Vol20_2

Norah Al-otabi. (2013). The Effectiveness of Social Networking Twitter (microblogging) on Academic Achievement and the Developing the Cooperative Learning Skills for Female Students in Second Grade Secondary in Computer Curriculum. E-learning \& Distance Education. 